\title{
Development and performance evaluation of a prototype electrically powered brush cutter
}

\author{
*Bello R. S, Baruwa A. \& Orisamuko F. \\ Department of Agricultural \& Bio-Environmental Engineering Technology, Federal College of \\ Agriculture, Ishiagu, Nigeria \\ *E-mail address: segemi2002@gmail.com
}

Keywords: Brush cutter, efficiency, power pack, blade, ergonomics

\begin{abstract}
An electrically operated brush cutter was developed and fabricated to eliminate inherent ergonomic designs and costs of imported brush cutters and also improve performance efficiency. The machine incorporated an electric power pack which provides 4 hours of continuous power for cutting, ergonomic design a ground wheel roller was introduced to reduce carpal disorder that could be associated with hand held brush cutters. Machine effective efficiency is rated at $46.67 \%$ and the blade cutting efficiency is $87.5 \%$. The minimum height of cut is $1.3 \mathrm{~mm}$ while the machine is capable of operating at variable conditions. The estimated cost of the machine is N10, 000.00 compare to the cost of imported machines
\end{abstract}

\section{INTRODUCTION}

Generally, grasses are found to survive in a variety of conditions and thus the need to curb their growth in order to enhance the beauty of our environment. The aesthetic value of environment is as important as food and shelter to the modern man (Okafor, 2013). As man evolved intellectually, brush cutting Mowing and cleaning of lawns and walkways have become a critical part of aesthetic design in building management and have invariably developed to an art. The earliest brush cutters were invented as early as 1830s by Edwin Beard Budding (Mandloi et al, 2011) who was said to have obtained the idea after watching a machine in a local cloth mill which used a cutting cylinder mounted on a bench to trim clothes for a smooth finish after weaving (Fossett, 2007). As technology advanced, grass cutting devices developed giving birth lawn mower and brush cutter, away from use of machetes, hoes and cutlasses to motorized grass cutters.

This technology had continued to advance and better techniques of grass cutting are being invented and constantly improved upon; many designs are available on commercial scale, each suited to specific purposes such as shrub cutting, lawn mowing and hedge trimmings which are comparatively very much thicker than grass and other common weeds. Among the types available in market, is the one sold under the commercial name of brush cutter.

In operation, brush cutters navigate through weeds, heavy brush and overgrown vegetation with ease. The welded steel frame design and engine positioning provide excellent balance regardless of the terrain. Existing engine trimmers suffer from high initial cost, high levels of engine noise, high fuel consumption rate and high operator fatigue on the long run (Cobb and Cooney, 2006; Reddy et al., 2010; Sujendran and Vanitha, 2014)

Manual mowing or slashing which is the most common and cheapest way of keeping the lawn clean involves a lot stress and inefficiency. Commercial brush cutters equally have certain inherent drawbacks, which can be eliminated by locally fabricated shrub cutter machine with some special features. They are expensive, generates a lot of noise, vibrations and has ergonomic effects on operator' hand, ears and waist (Muggleton et al., 1999). This paper intends to eliminate some of these drawbacks by developing, fabricating and evaluating the performance of an electrically operated brush cutter. 


\section{MATERIALS AND METHODS}

\section{Experimental machine description}

The experimental machine used for the study was developed at the metal fabrication of the Department of Agriculture \& Bio-Environmental Engineering, Federal College of Agriculture Ishiagu. The concept of hand held brush cutter which works similarly to a string trimmer to clear heavy foliage along the edges where larger brush cutters cannot gain enough access to cut. The major components of the machine include, a power pack, battery casing (housing), a 12V DC induction motor, cutter blade, roller wheel assembly, the blade and the frame (extension bar). The power pack (Figure) comprises of three essential components; two $6 \mathrm{~V}$ batteries, charging unit, power cables and connectors, a switch control, 4 diodes and a capacitor. The electrical circuit comprises of the induction coil, the battery, an electrical switch and connection cables.

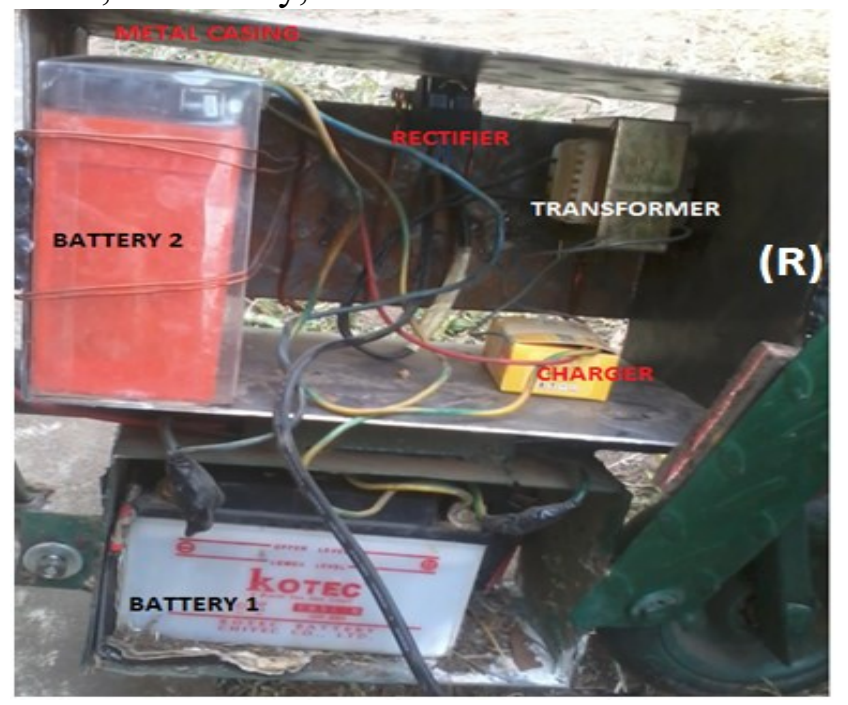

Figure 1: Power pack unit

The battery is the residual power source for the machine. It comprises of two $12 \mathrm{~V}$ batteries connected in parallel to increase the load carrying capacity from the initial 5Ah to $12 \mathrm{Ah}$. The charging unit comprises of a $12 \mathrm{~V}$ step-down transformer which steps down the 220 Volts AC to 15 Volts AC output. This is connected to four diodes to convert the 15 volts AC into a 15 volts D.C. A push type charging switch controls the charging system when connected to the AC mains.

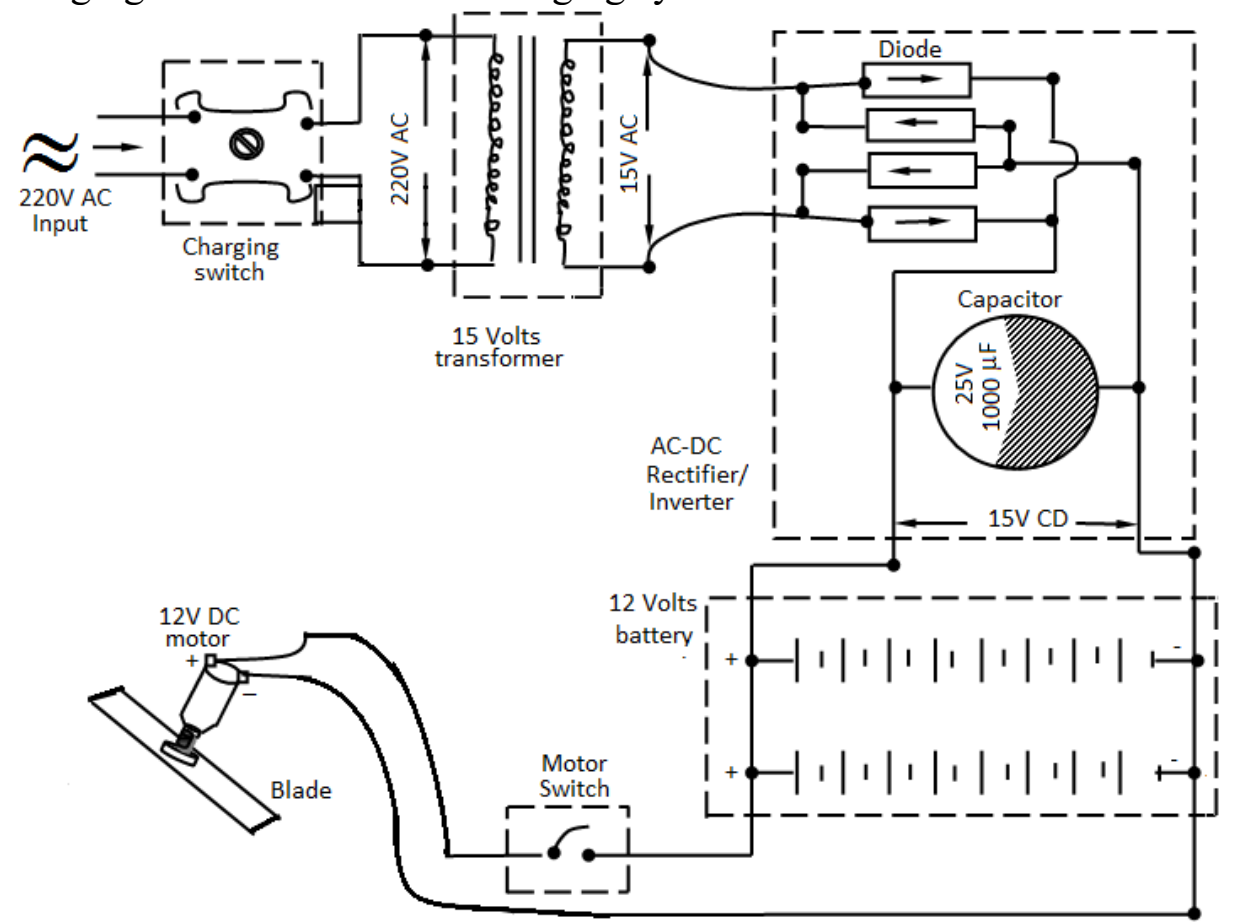

Figure 2: Circuit diagram for power pack 
The transformer is an output device which steps down the 220 Volts AC to 15 Volts AC output. The 15 Volts AC passes through rectification or an AC-DC inverter which comprises of four diodes intricately connected to serve the purpose of converting AC to DC. This is connected to four diodes (full-wave bridge) to convert the 15 volts AC into a 15 Volts D.C

The $15 \mathrm{~V}$ DC wave supplied passed through a $15 \mathrm{Volt}-1000 \mu \mathrm{F}$ capacitance rated capacitor for smoothing the rough waves into small rippers suitable for use by the induction coil. The smooth 15 Volts DC is then connected to the two 12 Volts batteries connected in parallel. The power cable is a flexible double core wire connector with a 3-pin plug that connects the machine to a 220 Volts AC input. The double edge, rectangular blade; $76.0 \mathrm{~mm}$ wide, $190.0 \mathrm{~mm}$ long and $2.0 \mathrm{~mm}$ thick, is attached to the induction motor spindle. A $250 \mathrm{~mm}$ diameter solid wheeler connected to the frame provides ease of equipment movement.

\section{MACHINE POWER REQUIREMENTS}

Material selection and development of the machine is based on numerous criteria which include horsepower requirements, motor efficiency, service power factor, ambient and operating temperature and speed. The induction motor (electric) power requirement is expressed by equation 1.

Where

$$
P_{k W}=\frac{I x V}{1000}(k W)=\frac{P_{k W}}{0.746}(h p)
$$

$P_{k W}=$ Electrical input power $(k W)$

$V=$ Input voltage $(12 \mathrm{~V})$

$I=$ Input direct current $(\mathrm{A}=3.3 \mathrm{amps})$

$P_{m}=$ mechanical output power

$P_{h p}=$ horsepower (hp)

The machine output power delivered in operating the system is expressed by:

$$
P_{m}=T \omega
$$

Where $\mathrm{T}$ is output torque, and $\omega$ is output angular velocity.

The continued increase in energy costs and emergence of energy saving applications necessitated the selection of the most efficient motor for a given application. The motor efficiency is expressed as

Where

$$
\eta_{m}=\frac{P_{m}}{P_{k W}}
$$

$\eta_{m}=$ energy conversion efficiency

$P_{m}=$ the mechanical output power

$P_{k W}=$ electrical input power

\section{Power factor}

When comparing motor efficiencies, the power factor must also be considered which is calculated by the following formula:

* For 3-phase motors only.

$$
\text { Power factor }=\frac{\text { Electrical Input power }}{\text { Volts } x \text { Amps } \times 1.73 *}
$$

The electrical energy consumption (E) is the actual energy demand made on existing electricity supply. This energy in kilowatt-hours $(\mathrm{kWh})$ per day is equal to the power $\mathrm{P}$ in watts $(\mathrm{W})$ multiply by the number of usage hours per day $t$ divided by 1000 watts per kilowatt:

$$
\mathrm{E}\left(\frac{\mathrm{kWh}}{\text { day }}\right)=\mathrm{P}(\mathrm{W}) \times \frac{\mathrm{t}\left(\frac{\mathrm{h}}{\text { day }}\right)}{1000\left(\frac{\mathrm{W}}{\mathrm{kW}}\right)}
$$

The electrical energy demand at full battery charge is expressed as the product of battery voltage, power rating in joules and square of time taken. This is expressed mathematically as 
Where

$$
E_{\text {batt }}=V x P_{r} x t^{2} \text { Joules }
$$

$E_{\text {batt }}=$ Electrical energy at battery full charge

$\mathrm{V}=$ Battery voltage

$P_{r}=$ Battery power rating in $\mathrm{Ah}$

$t=$ Time taken to charge $\left(\mathrm{sec}^{2}\right)$

Motor capacity $(\mathbf{k W})$ : The motor capacity is determined by determining the most suitable load, system and process application. The flow chart of the power supply and distribution is shown in Figure 3 below.

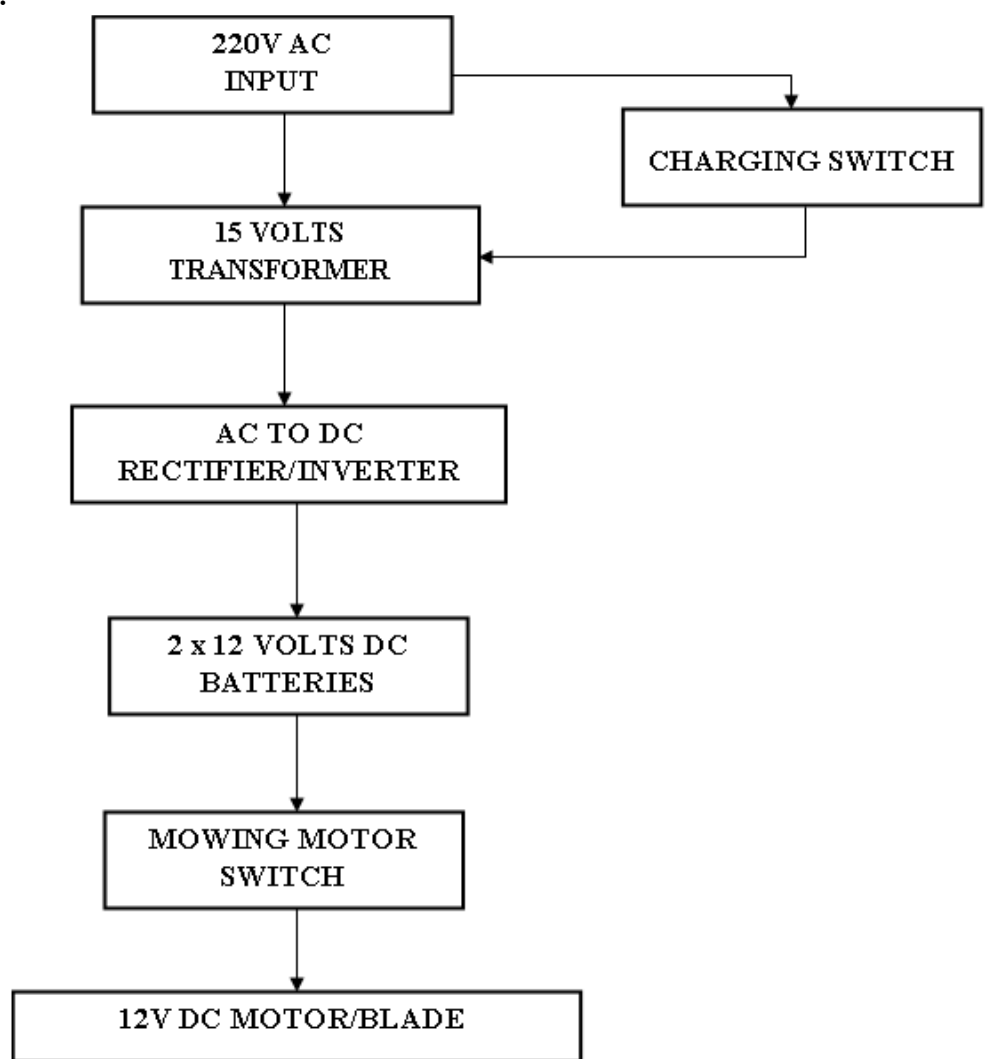

Figure 3: The flow chart of the power supply and distribution

\section{Machine performance tests}

Machine performance tests carried out include

- Blade cutting efficiency: \% of total number of plant smoothly cut at fixed height to total number of plant population-total number of rough cut

$$
\eta_{\text {blade }}=\frac{\text { Total number of smoothly cut plant }}{\text { Total plant population }} \times 100 \%
$$

- Machine performance efficiency: This is the ratio of \% plant smoothly cut per square area to total $\%$ of plant roughly cut per unit area of population

$$
\eta_{\text {per }}=\frac{\% \text { plant smoothly cut per square area }}{\% \text { plant roughly cut per square area }} \times 100 \%
$$

- Machine effective efficiency: This is the ratio of $\%$ plant cut per square area to total plant population.

$$
\eta_{\text {eff }}=\frac{\% \text { plant cut per square area }}{\text { Total plant population }} \times 100 \%
$$

Machine rated capacity: Total area effectively mowed at full battery charged $\mathrm{x}$ plant population factor.

The plant population on each field was estimated using the plant species with the highest frequency

$$
\text { Plant factor } p=\frac{\text { Highest plant frequency }}{\text { Total estimated plants }}
$$


Plant population factor is estimated by the average number of randomly sampled plants of different category and girth diameter that are found in specific area of the field. The plant population factor $P_{f}$ is given by the average total of plant population

$$
P_{f}=\frac{\text { Average } n \text { number of plant stand }}{\text { Area of land }\left(\mathrm{m}^{2}\right)}
$$

\section{Results and discussion}

Figure 4 below shows the experimental machine setup while Table 1 shows the specifications of the designed features, unit of measurements, descriptions and machine parameters.

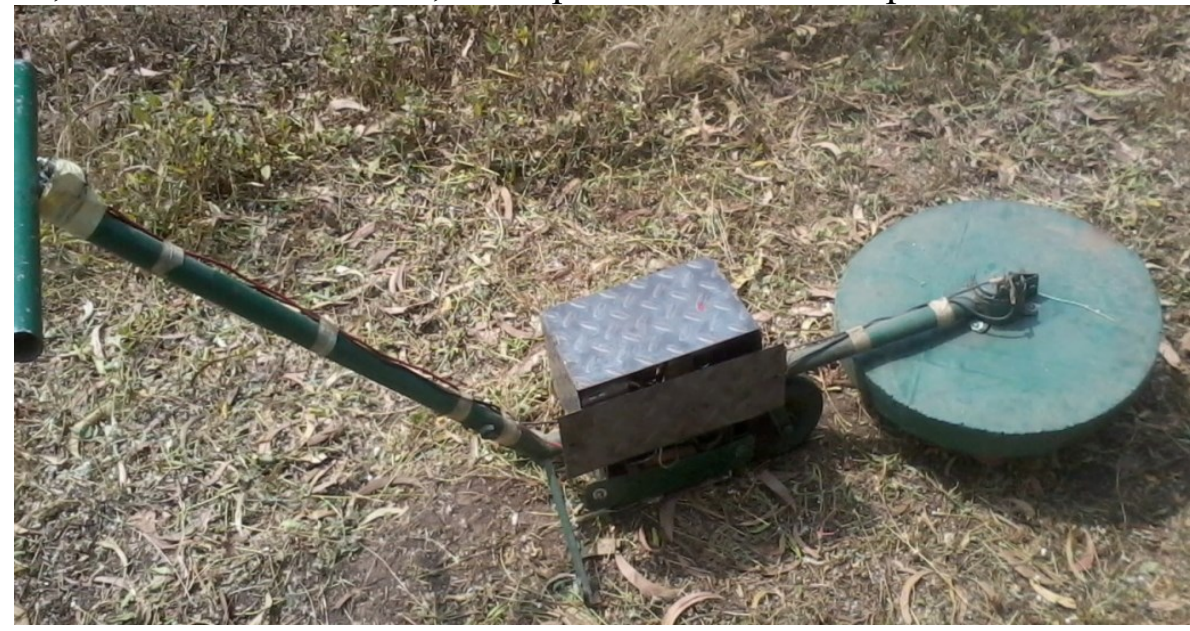

Figure 4: The flow chart of the power supply and distribution

Table 1: Machine specification and performance tests

\begin{tabular}{lc}
\hline \multicolumn{1}{c}{ Components } & Specifications \\
\hline Length (mm) & 1450 \\
Width (mm) & 1701 \\
Height (mm) & 700 \\
Cutting width (mm) & 430 \\
Cutting height $(\mathrm{mm})$ & 50 \\
Blade length (mm) & 401 \\
Blade width (mm) & 30 \\
Number of blade & Single straight blade \\
Roller wheel (solid tyre type) & $250 \mathrm{~mm}$ dia. \\
Net weight of machine (Kg) & 15 \\
\hline
\end{tabular}

Table 2 shows electric power requirement for the machine.

Table 2: Electric power requirements

\begin{tabular}{lc}
\hline \multicolumn{1}{c}{ Power requirements } & Specification \\
\hline Induction motor voltage $(\mathrm{V})$ & $12 \mathrm{~V}$ \\
Battery (2) Parallel connection & $12 \mathrm{Volts}$ \\
Total output voltage required & $12 \mathrm{~V}$ \\
Total output Amperage & $3.3 \mathrm{~A}$ \\
Power rating of battery (5Ah+7Ah) & $12 \mathrm{Ah}$ \\
Charging system \& accessories & AC-DC charging \\
Starter switch (1) & push type \\
\hline
\end{tabular}

\section{Field test}

The brush cutter was tested at idle speed for few minutes per time to ascertain that all components were well fixed. All minor corrections were made and the field test was carried out. The electrical connections worked accordingly and the machine effectively cut the lawn. The figure below shows the machine under test in one of the four (4) randomly selected areas measuring $1200 \times 1400 \mathrm{~mm}$. Four species of plants were identified in these selected fields; Sida acuta, Anxonopus Compressus, 
Tridax Procumbence and Imperata cylindrical. In all the mapped areas, sida acuta is predominant in all with an estimated $65 \%$ population.
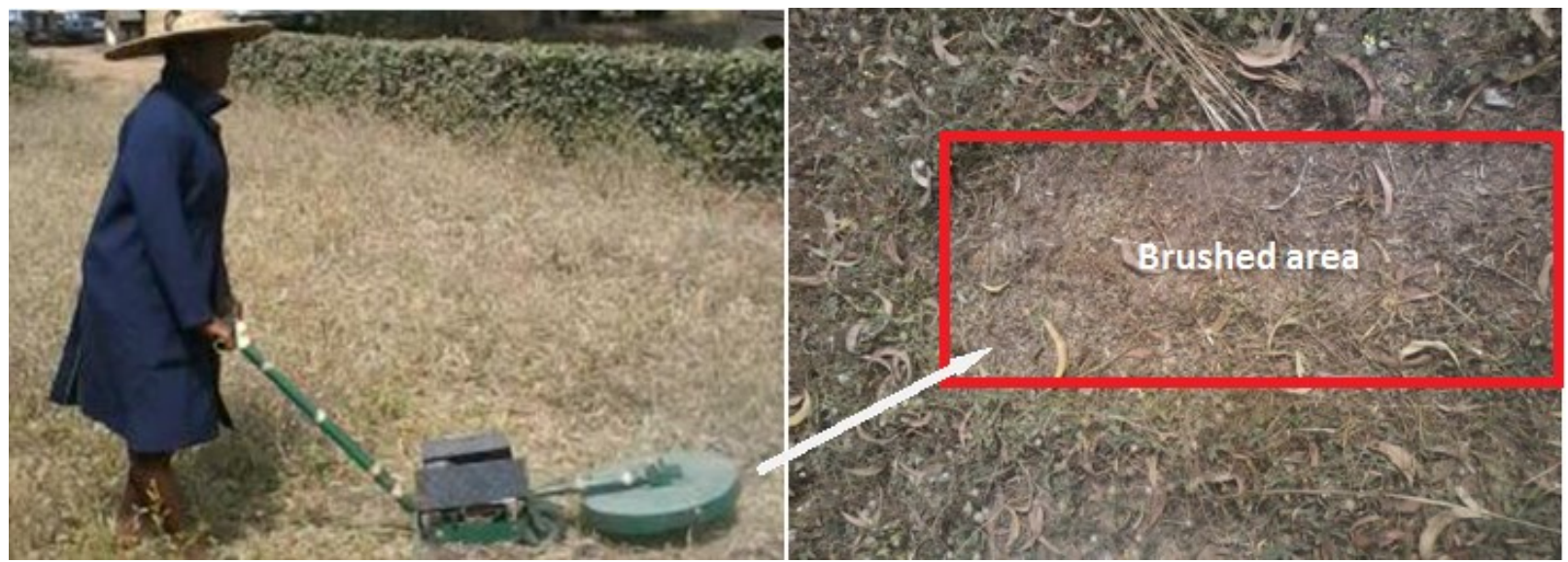

Figure 5: Field test

Table 3 below shows the different plant size and population frequency of the identified plant species in each area. The average total number of each size category is also presented in the table. From the table, the plants with highest frequency have diameter greater than $3.5 \mathrm{~mm}$.

Table 3: Size of plants and population of plant per unit area

\begin{tabular}{lccc}
\hline \multicolumn{1}{c}{ Sample area } & \multicolumn{3}{c}{ Plant population } \\
\hline Plant diameter & $>3.5(\mathrm{~mm})$ & $2.3(\mathrm{~mm})$ & $<2(\mathrm{~mm})$ \\
Area 1 & 20 & 18 & 10 \\
Area 2 & 5 & 10 & 10 \\
Area 3 & 50 & 20 & 15 \\
Area 4 & 40 & 20 & 10 \\
Average & 28.75 & 17 & 8.75 \\
\hline
\end{tabular}

Per unit area ( 700 by $600 \mathrm{~mm}$ ) measured, the maximum measured height plants that are smoothly cut and those roughly cut by the brush blade are $1.2 \mathrm{~mm}$ and $4.3 \mathrm{~mm}$ respectively. The estimated percentage cut for each ( $87 \%$ smooth cut, $23 \%$ rough cut) is an indication of high blade efficiency and better machine performance.

Table 4: Machine performance

\begin{tabular}{lc}
\hline \multicolumn{1}{c}{ Performance indicator } & Performance value \\
\hline Blade cutting efficiency (\%) & $87.5 \%$ \\
Machine effective efficiency & $46.67 \%$ \\
Maximum plant diameter cut & $4.3 \mathrm{~mm}$ \\
Minimum height of cut above ground & $1.2 \mathrm{~mm}$ \\
Length of operation at battery full charge & 4 hours \\
\hline
\end{tabular}

\section{CONCLUSION}

An electrically operated brush cutter has been developed and tested for performance. The following conclusion could therefore be drawn;

1. The electrical circuit incorporating a charging device provide opportunity for continuous operation up to 4 hours at full battery charge

2. The machine eliminated noise which is commonly associated with lawn mowers and brush cutters.

3. The light weight advantage makes maneuverability easy. 


\section{References}

[1] Basil Okafor, 2013. Simple Design of Self-Powered Lawn Mower. International Journal of Engineering and Technology Volume 3 No. 10, 933-938

[2] Cobb TK, Cooney WN, An KN. Aetiology of work-related carpal tunnel syndrome: the role of lumbrical muscles and tool size on carpal tunnel pressures. Ergonomics. 1996; 39 (1):103-7.

[3] Mandloi R. K., Rajesh GuptaB and A. Rehman, 2011. Design, Development and Testing of Low Capital and Operational Cost Shrub Cutting Machine Journal of Rangeland Science, 2011, Vol. 1, No. 2

[4] Muggleton JM, Allen R, Chappell PH. Hand and arm injuries associated with repetitive manual work in industry: a review of disorders, risk factors and preventive measures. Ergonomics. 1999; 42 (5):714-39.

[5] Patrick Fossett, 2007. The origins of golf and how it conquered the world. http://www.vertaria.com/documents/12en_VGo_Art_20070115PF_OriginsOfGolf_UK.pdf?

[6] Reddy Appala k., N. Mahesh, L. Harini, R Sirkanth andJ. Srinivas, 2010. Design and analysis of a revised grass trimming device. Jor of Sc \& Indut Res Vol 69, pp 39-42.

[7] Sujendran and Vanitha, .2014. Smart Lawn Mower for Grass Trimming. International Journal of Science and Research (IJSR) ISSN (Online): 2319-7064 Volume 3 Issue 3, 299-303 www.ijsr.net 